\title{
177. On the Hydroxylation of Anthranilic Acid and Kynurenine
}

\author{
By Yahito Kotake, Yukio Shibata, and Akio Toratani \\ Biochemistry Department of Wakayama Medical College \\ (Comm. by Y. Kotake, M.J.A., Dec. 13, 1956)
}

Introduction. Both anthranilic acid and kynurenine were first successfully discovered by Yashiro Kotake et al., ${ }^{1)}$ as the intermediate metabolites of tryptophan in the animal. It was further found out by Yashiro $\mathrm{Kotake}^{2)}$ and Beadle ${ }^{3)}$ that both of these substances can be hydroxylated in vivo into 5-OH-anthranilic acid and 3-OH-kynurenine respectively. But the definite mechanism of such hydroxylation remained unknown.

The authors of this paper, therefore, made an attempt to hydroxylate anthranilic acid in model ascorbic acid system by Udenfriend ${ }^{4)}$ and to ascertain whether anthranilic acid could really be hydroxylated and performed paper-partition-chromatographical examination. Furtheremore, with a view to obtain the results of the same nature in vivo, they adopted another hydroxylating method in which the cyclohexene ring of 1.5-dimethyl-5-cyclohexenyl barbituric acid was hydroxylated with liver homogenate by Y. Tochino, ${ }^{5)}$ and in his experiment, he has observed the inhibitory action of such systems as cytochrome $\mathrm{c}$ and cytochrome oxidase against the enzymatic action concerned with such hydroxylation. In other words, by employing KCN-containing enzyme system as shown in Fig. 2 and making use of liver homogenate, both the decrease rates of anthranilic acid and the paper-partition-chromatographical results were examined. The same experiment with regard to kynurenine was also examined.

Experiments and results. 1. Hydroxylation of anthranilic acid with Udenfriend's model ascorbic acid system.

Model ascorbic acid system with which Udenfriend has successfully hydroxylated some aromatic compounds was brought by the authors to act on anthranilic acid. First, $142 \mu \mathrm{M}$ ascorbic acid, $15 \mu \mathrm{M}$ ferrous sulfate, and $80 \mu \mathrm{M}$ EDTA were dissolved in $3 \mathrm{ml}$ of $0.1 \mathrm{M}$ ( $\mathrm{pH}$ 5.5) phosphate buffer solution, and thereto was added $60 \mu \mathrm{M}$ of anthranilic acid so as to obtain reaction mixture at $35^{\circ} \mathrm{C}$ for one hour in a Wahrburg's thermostat. The solution was subjected to quantitative analysis in accordance with Bratton-Marshall's method and the remaining anthranilic acid was measured.

In performing paper-partition-chromatographical examination, $1000 \times$ solution of each system was made use of. Rf value, color- 
reactions, and absorption spectrums of the spots obtained were tested.

Method: One-dimensional and ascending.

Filter paper: Toyo filter paper No. 52.

Developer: $n$-Butanol, acetic acid, and water (4:1:1).

Developing time: $12 \mathrm{hrs}$.

As shown in Fig. 1, the fluorescent spot of anthranilic acid was found to decrease remarkably and instead of it, there were presented other spots such as were presumable to be those of 3-OH-anthranilic and 5-OH-anthranilic acids. On further examination by means of color-reaction and ultraviolet spectrum, the spots obtained were confirmed to be same with the said two substances. It was further found out that if xanthurenic acid was added to the afore-mentioned system, the hydroxylation of anthranilic acid could be inhibited in a remarkable degree.

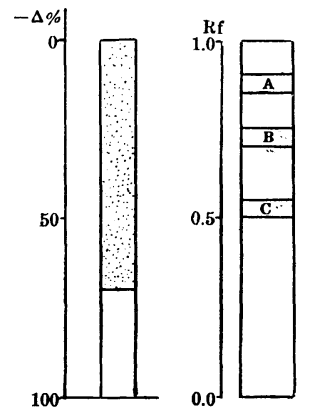

Fig. 1

142 $\mu \mathrm{M}:$ Ascorbic acid

15 $\mu \mathrm{M}$ : Ferrous sulfate

$80 \mu \mathrm{M}:$ EDTA

in $3 \mathrm{ml}$ of $0.1 \mathrm{M}$ phosphate buffer ( $\mathrm{pH}$ 5.5)

$60 \mu \mathrm{M}$ : Anthranilic acid

A: Anthranilic acid

B: 3-OH-Anthranilic acid

C: 5-OH-Anthranilic acid

Developer

n-Butanol 4

Acetic acid 1

Water 1

Developing time $12 \mathrm{hrs}$.

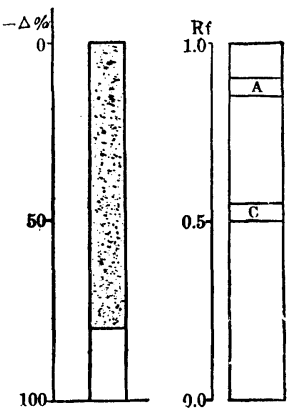

Fig. 2

1 mM: Potassium cyanide

$14.3 \mathrm{mM}$ : Succinate

$12.5 \mathrm{mM}$ : Nicotinamide

$6.25 \mathrm{mM}$ : Magnesium chloride in $3 \mathrm{ml}$ of $0.1 \mathrm{M}$ phosphate buffer ( $\mathrm{pH}$ 7.2)

1 mM: Anthranilic acid

$2 \mathrm{ml}$ : Liver homogenate in phosphate buffer (pH 7.2) or $33 \%$ isotonic $\mathrm{KCl}$-liver homogenate

Table I. Color-reaction in P.P.C. examination

\begin{tabular}{c|c|c|c|c|c|c}
\hline & Fluorescence & $\begin{array}{c}\text { Pauly's diazo } \\
\text { reagent }\end{array}$ & $\begin{array}{c}\text { Ehrlich's } \\
\text { aldehyde }\end{array}$ & Millon & Reduction & $\begin{array}{c}\text { Acetone } \\
\text { alkali }\end{array}$ \\
\hline B & Blue & $\begin{array}{c}\text { Pale yellowish } \\
\text { brown }\end{array}$ & $\begin{array}{c}\text { Pale } \\
\text { orange }\end{array}$ & \pm & + & Intensified \\
\hline C & Blue &,, &, & \pm & + &, \\
\hline
\end{tabular}


2. Hydroxylation of anthranilic acid with liver homogenate. When attempted with liver homogenate, no hydroxylation of anthranilic acid is possible. And so in this experiment, the authors used the above-mentioned Tochino's method employing KCN to check cytochrome $\mathrm{c}$ and cytochrome oxidase in liver homogenate and thereby succeeding in hydroxylating anthranilic acid as shown below.

$10^{-3} \mathrm{M}$ potassium cyanide, $1.43 \times 10^{-2} \mathrm{M}$ succinate, $1.25 \times 10^{-2} \mathrm{M}$ nicotinamide, and $6.25 \times 10^{-3} \mathrm{M}$ magnesium chloride were dissolved in $3 \mathrm{ml}$ of $0.1 \mathrm{M}$ ( $\mathrm{pH} \mathrm{7.2)}$ phosphate buffer solution and thereto was added $10^{-3} \mathrm{M}$ anthranilic acid. Subsequent to it, $2 \mathrm{ml}$ of liver homogenate in $33 \%$ isotonic $\mathrm{KCl}$ solution (or phosphate buffer solution) was further added and the reaction was made to proceed for one hour and at $35^{\circ} \mathrm{C}$ as in the foregoing experiment.

Next, when the reaction was over, the supernatant was obtained by means of a centrifuge. A portion of the supernatant was further deproteinized with alcoholic solution of boric acid. By making use of these two kinds of supernatant, both quantitative analysis and paper-partition-chromatographical examination of the remaining anthranilic acid were performed. The results thus obtained were shown in Fig. 2. What was more, ultraviolet absorption test revealed the production of 5-OH-anthranilic acid in both experiments of 1 and 2 (Fig. 3). Ultraviolet absorption spectrum of 5-OH-anthranilic acid produced as a result of hydroxylation of anthranilic acid either with model ascorbic acid system or with liver homogenate was also examined (Fig. 3).

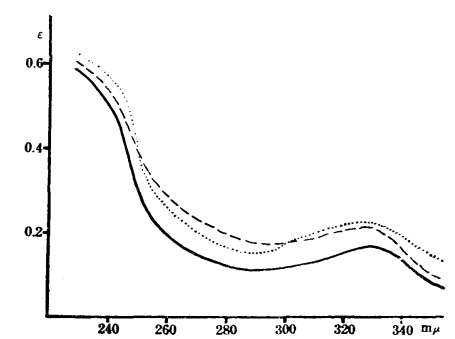

Fig. 3. Ultraviolet absorption spectrum

Synthetic substance

...... Model ascorbic acid system

_- Hydroxylating enzyme system
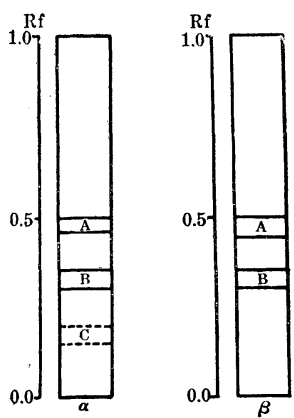

Fig. 4. Hydroxylation of kynurenine

$\alpha$ : Model ascorbic acid system

$\beta$ : Hydroxylating enzyme system

A: Kynurenine

B: 3-OH-Kynurenine

$\mathrm{C}$ : 5-OH-Kynurenine

3. Hydroxylation of kynurenine.

Hydroxylation of kynurenine was performed by the same experimental method as in the foregoing two experiments and 3-OH-kynurenine was obtained (Fig 4, Table II). Apart from this experiment 
of the authors', Hayashi, et al. have recently taken up this matter in the U. S. A. and obtained results of the same nature.

Anyway, this discovery that kynurenine can be hydroxylated by the action of the afore-mentioned enzyme system into 3-OH-kynurenine is a matter of great interest, since its mechanism has long left unknown.

Table II. Hydroxylation of kynurenine performed with liver homogenate and color-reaction in P.P.C. examination

\begin{tabular}{|c|c|c|c|c|c|}
\hline $\mathrm{Rf}$ & Fluorescent color & Pauly's diazo & Ehrlich's aldehyde & Ninhydrin & Reduction \\
\hline 0.32 & Bluish green & Pale yellow & Red & + & + \\
\hline \multicolumn{6}{|c|}{ Ultraviolet spectrum } \\
\hline \multicolumn{2}{|r|}{$\mathrm{pH} 7.2$} & \multicolumn{3}{|c|}{$374 \mathrm{~m} \mu$ (model ascorbic acid system) } & \\
\hline & 248 and & $310 \mathrm{~m}_{\mu}$ (both & system) & & \\
\hline
\end{tabular}

It is further to be noted that in 1954, Dalgliesh reported results of the same nature (anthranilic acid $\rightarrow 3-\mathrm{OH}$ - and 5-OH-anthranilic acid, kynurenine $\rightarrow 3-\mathrm{OH}-\mathrm{kynurenine)}$ obtained by means of Udenfriend's method.

In conclusion, we heartly thank Prof. Yashiro Kotake for his pertinent advices and encouragement.

\section{References}

1) Yashiro Kotake: Mitteilung der medizinischen Gesellschaft zu Osaka, 42, 1900 (1943).

2) See 1).

3) G. W. Beadle, H. K. Mitchell, and J. F. Nyc: Proc. Nat. Acad. Sci., 33, 155 (1947).

4) Sidney Udenfriend, Caroll T. Clark Julius Axelrod, and Bernard B. Brodie: J. Biol. Chem., 208, 731 (1954).

5) Yoshihiro Tochino: Wakayama Medical Reports, 3, 27 (1956).

6) C. E. Dalgliesh: Biochem. J., 54, 14 (1954). 